\title{
Fluorescent Ratiometric MFC Probe Sensitive to Early Stages of $\alpha$-Synuclein Aggregation
}

\author{
Dmytro A. Yushchenko, ${ }^{\dagger}$ Jonathan A. Fauerbach, ${ }^{\ddagger}$ Shyamala Thirunavukkuarasu, ${ }^{\dagger}$ \\ Elizabeth A. Jares-Erijman, ${ }^{\ddagger}$ and Thomas M. Jovin ${ }^{\star, \dagger}$ \\ Laboratory of Cellular Dynamics, Max Planck Institute for Biophysical Chemistry, Am Fassberg 11, \\ 37077 Göttingen, Germany and Departamento de Química Orgánica, Facultad de Ciencias Exactas y Naturales, \\ Universidad de Buenos Aires, CIHIDECAR, CONICET, 1428 Buenos Aires, Argentina
}

Received April 5, 2010; E-mail: tjovin@gwdg.de

The aggregation of the 140aa protein $\alpha$-synuclein (AS) is associated with a prominent cytopathological manifestation of Parkinson's disease (PD), the deposition of dense tangles of fibrils with a characteristic cross- $\beta$ amyloid structure in dopaminergic neurons of the substantia nigra of the midbrain. ${ }^{1}$ Extrinsic fluorescent dyes such as thioflavin $\mathrm{T}$ (ThT) display changes in intensity, spectral distribution, and polarization upon binding to amyloid fibrils and are extensively used for their quantitation and visualization. ${ }^{2}$ Unfortunately, aggregation assays generally require periodic sampling of the inherently complex molecular populations, leading to poor reproducibility and insufficient definition of the reaction course. More importantly, most probes are insensitive to the early oligomeric states of AS aggregation presumed to mediate the cytotoxic processes leading to the progression of PD. ${ }^{1 \mathrm{c}, 3}$ Improved tools for monitoring AS aggregation in vitro and in vivo are urgently required.

Environment-sensitive dyes are particularly useful reporters of protein aggregation. ${ }^{4} \mathrm{We}$ have previously described the utility of pyrene $^{5 \mathrm{a}}$ and aminonaphthalenes ${ }^{5 \mathrm{~b}}$ for monitoring the various stages of AS aggregation. In addition, fluorescence correlation (FCS $)^{6}$ and energy transfer (FRET) ${ }^{6,7 a}$ techniques using conventional dyes ${ }^{6}$ and expression probes ${ }^{7 a}$ provide "early reporting" and can be applied in combination with functionalized nanoparticles in living cells. ${ }^{7 \mathrm{~b}}$

The 3-hydroxychromones (3HCs) constitute an exceptional family of fluorophores with unique environmental sensitivity. These compounds exhibit a rapid (subns) excited-state intramolecular 3-hydroxyl $\rightarrow$ 4-carbonyl proton transfer (ESIPT), resulting in distinct emissions from both the initial "normal" excited state $\left(\mathrm{N}^{*}\right)$ and the ESIPT phototautomer product $\left(\mathrm{T}^{*}\right)$. The differential response of the $\mathrm{N}^{*}$ and $\mathrm{T}^{*}$ bands to environmental changes is conveniently expressed as the ratio of band intensities $I_{\mathrm{T}^{*}} / I_{\mathrm{N}^{*}}\left(\mathrm{~T}^{*} /\right.$ $\mathrm{N}^{*}$ ratio) and other spectral relationships. ${ }^{8}$ A decrease in the polarity and $\mathrm{H}$-bonding (donor) capacity of the microenvironment favors the ESIPT reaction of $\mathrm{HCs}$, thereby increasing the relative intensity of the $\mathrm{T}^{*}$ band. These unique properties have led to the application of $\mathrm{HCs}$ as membrane probes and as sensors of protein-DNA, DNA-polycation, and protein-protein interactions. ${ }^{8,9}$

We have previously reported that some $3 \mathrm{HCs}$ reveal differences in the supramolecular organization of amyloid fibrils formed by wild type (WT) AS and disease-related familial mutants. ${ }^{10}$ In this work we introduce sensor molecules consisting of covalent adducts of Ala-to-Cys mutants of AS with a thiol-reactive (maleimide) probe (MFC) based on 2-(2-furyl)-3-hydroxychromone FC ${ }^{9,11}$ (Figure 1). They are representative of the new, versatile ESIPT probes of amyloid aggregation, with unprecedented sensitivity for the initial stages of reaction.

\footnotetext{
Max Planck Institute for Biophysical Chemistry.

* Universidad de Buenos Aires.
}

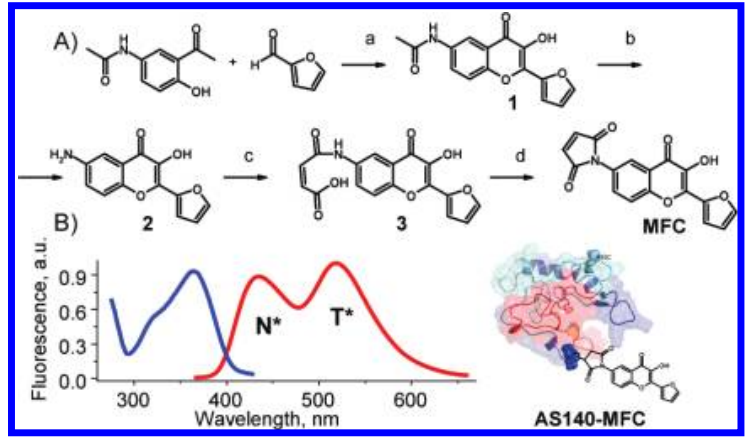

Figure 1. (A) Scheme for the synthesis of the MFC probe. (B) Diagramatic representation of AS140-MFC and its fluorescence excitation (blue) and emission (red) spectra at $\mathrm{pH} 6.2$ and $25^{\circ} \mathrm{C}$.

The steps used in the synthesis of MFC are shown in Figure 1A and documented in the Supporting Information (SI). The particular AS construct featured here and denoted AS140-MFC is a Cys mutant of AS in position 140 (C-terminus) reacted with MFC. The labeled protein AS140-MFC has two well-defined emission bands (Figure $1 \mathrm{~B}$; SI) with a $\mathrm{T}^{*} / \mathrm{N}^{*}$ ratio $\left(1.1\right.$ at $\left.25^{\circ} \mathrm{C}\right)$ close to that (1.2) for a reference compound, the conjugate of MFC with acetylcysteine (SI). This finding is consistent with the classification of AS as an intrinsically disordered protein. ${ }^{1}$

AS140-MFC is suitable for the continuous monitoring of protein aggregation and, in contrast to ThT, is sensitive to the early and intermediate stages of the overall reaction (Figure 2). We initiated the aggregation of a mixture of WT AS and 2.5\% AS140C-MFC ( $150 \mu \mathrm{M}$ total protein, $\mathrm{pH} 6.2$ ) by exposure to $37^{\circ} \mathrm{C}$ with vigorous agitation and acquired emission spectra as a function of time. In parallel, we sampled the reaction periodically with the ThT assay. The time course of a number of parameters derived from the spectra are featured in Figure 2A. The most notable spectroscopic feature was a dramatic (15-fold) increase in the $\mathrm{T}^{*}$ band intensity, with a smaller, 2-fold increase of the $\mathrm{N}^{*}$ band. The net effect was a 9.5fold rise in the $\mathrm{T}^{*} / \mathrm{N}^{*}$ ratio to a peak value of 8.8 at $20 \mathrm{~h}$, decreasing to 7.6 at the end of the reaction $(70 \mathrm{~h})$.

Particularly noteworthy was that these and other changes preceded the progress curve defined by the conventional ThT signal (Figure 2B). The sequence of $t_{1 / 2}$ values (transition midpoints) were as follows: $\mathrm{T}^{*}$ peak wavelength $(5.3 \mathrm{~h}), \mathrm{T}^{*}$ peak intensity $(12.5$ h), $\mathrm{N}^{*}$ peak intensity $(13.8 \mathrm{~h}), 355 \mathrm{~nm}$ scattering ( $23.5 \mathrm{~h}$ ), and ThT signal $(34 \pm 2 \mathrm{~h})$. These values and other qualitative and quantitative features of the progress curves (early bathochromic shift of the $\mathrm{T}^{*}$ band, intersection of $\mathrm{T}^{*}$ and $\mathrm{N}^{*}$ fractional transitions, transient maximum of the $\mathrm{T}^{*}$ band) constitute unambiguous evidence for reaction intermediates $(I)$ detected by the ESIPT probe by virtue of differing significantly from the monomeric and amyloid 
fibrillar $(A F)$ forms of AS. Such transient pre- $\beta$ (see below) conformational switching has also been detected by the sophisticated application of FCS and FRET. ${ }^{6}$ We visualized the intermediates by AFM (an example is shown in the SI; a detailed description will be supplied in a separate communication) and are currently attempting their biochemical isolation, a difficult undertaking due to their elusive nature. ${ }^{6}$ Light scattering at $355 \mathrm{~nm}$ largely paralleled the ThT signal but judging from the lower $t_{1 / 2}$ appeared to sense some forms of $I$ as well as $A F .^{12}$

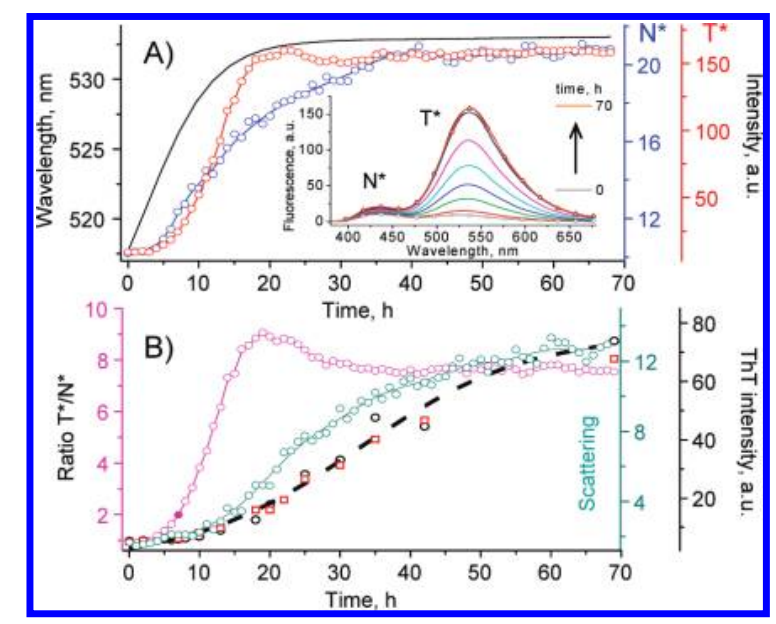

Figure 2. Aggregation of 2.5\% AS140-MFC $+97.5 \%$ WT AS $(150 \mu \mathrm{M}$ total protein) at $37^{\circ} \mathrm{C}$. (A) Derived spectral signals, normalized by their changes between the start and end of the incubation and plotted according to their respective scales: $\mathrm{T}^{*}$ peak wavelength (black curve), $\mathrm{T}^{*}$ peak intensity (red), $\mathrm{N}^{*}$ peak intensity (blue). The $\mathrm{N}^{*}$ peak wavelength (not shown) did not vary significantly $(433 \pm 2 \mathrm{~nm})$. Insert: repetitive emission spectra during aggregation (excitation $345 \mathrm{~nm}$ ). (B) $\mathrm{T}^{*} / \mathrm{N}^{*}$ ratio (magenta), scattering at $355 \mathrm{~nm}$ (dark cyan), and ThT signal (black dashed line, fit according to ref 10); ThT signal of the control WT sample (red squares).

The large increase in the $\mathrm{T}^{*} / \mathrm{N}^{*}$ ratio (Figure $2 \mathrm{~B}$ ) and quantum yield (SI) as well as the red-shifted $\mathrm{T}^{*}$ band exhibited by AS140CMFC upon aggregation reflect a transfer of the probe to a significantly less protic (H-bonding) and moderately less polar environment. This conclusion is based on the comparison of the properties of the aggregated protein with those reported for the furyl chromone in aprotic solvents, particularly DMF and acetonitrile. ${ }^{11 \mathrm{~b}}$ The conjugate of MFC with acetylcysteine also had a much a higher $\mathrm{T}^{*} / \mathrm{N}^{*}$ ratio $(\sim 17)$ in DMF than in aqueous solution $(\mathrm{SI})$. It follows that the spectral changes in AS140C-MFC during thermal-induced aggregation of AS to both $I$ and $A F$ reflect a diminished exposure of the C-terminus to the aqueous solution. The discrepancies in the temporal evolution of the MFC signals compared to those of ThT and light scattering also suggest that at least some $I$ lack the aromatic-hydrophobic groove spanning the consecutive $\beta$-strands proposed to constitute the minimal ThT binding site of amyloid fibrils. ${ }^{13} \mathrm{CD}$ spectra provided further evidence for the absence of significant $\beta$-sheet secondary structure (SI). MFC derivatives of cysteines introduced at positions 18 and 90 also exhibited distinctive spectral signatures (data not shown).

The persistence of the enhanced MFC emission in $A F$ is notable in view of the conclusion from other studies, e.g. based on solidstate NMR, ${ }^{14}$ that the C-terminus of fibrillar AS is exposed and mobile. The temporal range of measurement is a key issue. The steady-state fluorescence anisotropy of the $\mathrm{T}^{*}$ band in the monomer $(0.20 \pm 0.03)$ and $A F(0.31 \pm 0.04)$ were consistent with prior evidence $^{5 a}$ for immobilization of virtually all protein segments on the nanosecond time scale.

An important practical advantage of the MFC probe is the inherently continuous nature of the aggregation assay, providing more detailed, multiparameter data than the usual ThT-based sampling protocols. The procedure can be implemented on many instrumentation platforms and is easily automated. We anticipate that AS140-MFC and related constructs will constitute useful tools for screening inhibitors or reversers of AS aggregation, as well as being readily transferable to other proteins undergoing pathological as well as functional ${ }^{1 \mathrm{a}, 15}$ amyloid transitions.

Acknowledgment. We thank Drs. A. Demchenko, V. Shvadchak, D. Arndt-Jovin, and R. Klement for valuable discussions and U. Plessmann for mass spectra. Supported by the Max Planck Society (E.J.E., Partner Group grant; Toxic Protein Conformation project); Cluster of Excellence 171 of the DFG Centre for Molecular Physiology of the Brain (DFG CMPB); Argentine agencies AnpCyT, CONICET, UBA (E.J.E.). DAY received postdoctoral fellowships from EU FP6 STREP Fluoromag project 037465II and the Marie Curie Foundation.

Supporting Information Available: Synthesis and characterization of MFC dye. Preparation of AS and labeling procedure with MFC. Spectral properties of AS and AFM images at the different steps of aggregation. This material is available free of charge via the Internet at http://pubs.acs.org.

\section{References}

(1) (a) Chiti, F.; Dobson, C. M. Annu. Rev. Biochem. 2006, 75, 333. (b) Uversky, V. N. Curr. Protein Pept. Sci. 2008, 9, 507. (c) Waxman, E. A.; Giasson, B. I. Biochim. Biophys. Acta 2009, 1792, 616.

(2) Groenning, M. J. Chem. Biol. 2010, 3, 1.

(3) (a) Lashuel, H. A.; Hartley, D.; Petre, B. M.; Walz, T.; Lansbury, P. T., Jr. Nature 2002, 418, 291. (b) Outeiro, T. F.; Putcha, P.; Tetzlaff, J. E.; Spoelgen, R.; Koker, M.; Carvalho, F.; Hyman, B. T.; McLean, P. J. PLoS One 2008, 3, e1867.

(4) Munishkina, L. A.; Fink, A. L. Biochim. Biophys. Acta 2007, 1768, 1862.

(5) (a) Thirunavukkuarasu, S.; Jares-Erijman, E. A.; Jovin, T. M. J. Mol. Biol. 2008, 378, 1064. (b) Celej, M. S.; Jares-Erijman, E. A.; Jovin, T. M. Biophys. J. 2008, 94, 4867.

(6) Nath, S.; Meuvis, J.; Hendrix, J.; Carl, S. A.; Engelborghs, Y. Biophys. J. 2010, 98,1 .

(7) (a) Roberti, M. J.; Bertoncini, C. W.; Klement, R.; Jares-Erijman, E. A.; Jovin, T. M. Nat. Methods 2007, 4, 345. (b) Roberti, M. J.; Morgan, M.; Menendez, G.; Pietrasanta, L. I.; Jovin, T. M.; Jares-Erijman, E. A. J. Am. Chem. Soc. 2009, 131, 8102.

(8) (a) Demchenko, A. P.; Mely, Y.; Duportail, G.; Klymchenko, A. S. Biophvs. J. 2009, 96, 3461. (b) Shynkar, V. V.; Klymchenko, A. S.; Kunzelmann, C.; Duportail, G.; Muller, C. D.; Demchenko, A. P.; Freyssinet, J.-M.; Mely, Y. J. Am. Chem. Soc. 2007, 129, 2187.

(9) (a) Enander, K.; Choulier, L.; Olsson, A. L.; Yushchenko, D. A.; Kanmert, D.; Klymchenko, A. S.; Demchenko, A. P.; Mely, Y.; Altschuh, D. Bioconjugate Chem. 2008, 19, 1864. (b) Klymchenko, A. S.; Shvadchak, V. V.; Yushchenko, D. A.; Jain, N.; Mely, Y. J. Phys. Chem. B 2008, 112, 12050. (c) Shvadchak, V. V.; Klymchenko, A. S.; de Rocquigny, H.; Mely, Y. Nucleic Acids Res. 2009, 37, e25. (d) Choulier, L.; Shvadchak, V. V.; Naidoo, A.; Klymchenko, A. S.; Mely, Y.; Altschuh, D. Anal. Biochem. 2010, 401, 188 .

(10) (a) Celej, M. S.; Caarls, W.; Demchenko, A. P.; Jovin, T. M. Biochemistry 2009, 48, 7465. (b) Caarls, W.; Celej, M. S.; Demchenko, A. P.; Jovin, T. M. J Fluoresc 2010, 20, 181.

(11) (a) Avilov, S. V.; Bode, C. F.; Tolgyesi, G.; Klymchenko, A. S.; Fidy, J.; Demchenko, A. P. Int. J. Biol. Macromol. 2005, 36, 290. (b) Das, R.; Klymchenko, A. S.; Duportail, G.; Mely, Y. Photochem. Photobiol. Sci. 2009, 8,1583 .

(12) The $90^{\circ}$ scattering measurement is more convenient than turbidity ${ }^{6}$ in that it is obtained as an integral part of the recorded emission spectrum by selecting a region at the red-edge of the excitation band that yields signal levels comparable to those of fluorescence (SI).

(13) Wu, C.; Biancalana, M.; Koide, S.; Shea, J.-E. J. Mol. Biol. 2009, 391, 784.

(14) Heise, H.; Celej, M. S.; Becker, S.; Riedel, D.; Pelah, A.; Kumar, A.; Jovin, T. M.; Baldus, M. J. Mol. Biol. 2008, 380, 444.

(15) Fowler, D. M.; Koulov, A. V.; Balch, W. E.; Kelly, J. W. Trends Biochem. Sci. 2007, 32, 217.

JA102838N 